\title{
The Influence of BMI and Predictors of Disordered Eating and Life Satisfaction on Postmenopausal Women
}

\author{
SÓNIA F. GONÇALVES, ELSA SILVA, and A. RUI GOMES \\ School of Psychology, University of Minho, Braga, Portugal
}

\begin{abstract}
This study aims to compare eating behaviors, body satisfaction, exercise, and life satisfaction between normal-weight and overweight postmenopausal women and to examine the predictors of disordered eating and life satisfaction among postmenopausal women ( $\mathrm{n}=294)$. The overweight group had more eating disordered behavior, more body dissatisfaction, and lower physical quality of life. The increase of age predicted less disordered eating. Higher BMI, the perception of an ideal weight lower than the current one, lower body satisfaction, and physical quality of life predicted disordered eating. Higher body satisfaction, less psychosocial discomfort, and a greater degree of sexual symptom discomfort predicted life satisfaction.
\end{abstract}

KEYWORDS postmenopausal, eating disturbance, body satisfaction, life satisfaction

\section{INTRODUCTION}

Eating disorders are psychiatric disorders associated with profound morbidity and dramatically elevated mortality rates (Pike et al., 2008). These disorders are common among adolescents and young women in Western societies. However, a growing body of research demonstrates that eating disorders and disordered eating (as opposed to clinically diagnosable eating disorders) remains at high levels in midlife (McLean, Paxton, \& Wertheim, 2010). In two population-based studies (Lucas, Beard, O'Fallon, \& Kurland, 1991; Lucas,

Address correspondence to Sónia F. Gonçalves, School of Psychology, University of Minho, Campus de Gualtar, Braga, Portugal. E-mail: sgoncalves@psi.uminho.pt 
Crowson, O'Fallon, \& Melton, 1999), estimates of incidences of anorexia nervosa ranged from 7.2 to 7.7 per 100,000 women aged 40-59 years. Estimates of the point prevalence rate of bulimia nervosa among middle-aged women ranged from $0.9 \%$ to $1.0 \%$ (Johnson, Spitzer, \& Williams, 2001). Regarding regular binge eating (twice or more episodes by week), Freitas, Appolinario, Souza, and Sichieri (2008) in a study with Brazilian midlife women found a prevalence of $11.5 \%$ and found that binge eating episodes were positively correlated with body mass index (index of weight-for-height-BMI) and negatively correlated with age and self-rated health. According to Keel, Gravener, Joiner, and Haedt (2010), the estimated point prevalence rate for clinical eating disorders in middle-aged women is $4.5 \%$. There is also some evidence to suggest that maladaptive eating attitudes and behaviors are common during midlife. For example, according to the study of Gravener, Haedt, Heatherton, and Keel (2008), 11\% of middle-aged women reported that they either usually or always dieted. In another study, $29.7 \%$ of middle-aged women from various ethnic backgrounds reported dissatisfaction with eating patterns, and $13.4 \%$ endorsed eating little or nothing for a day or longer to control weight (Marcus, Bromberger, Wei, Brown, \& Kravitz, 2007). Pérez, Hernández, Clarke, and Joiner (2007) found that the overall level of bulimic symptomatology did not differ between young and middle-aged women.

Despite these numbers, only recently has increased attention been paid to postmenopausal women. In fact, postmenopausal women have been largely neglected in studies of eating disorders and disordered eating, highlighting the need for further research (Slevec \& Tiggemann, 2011) and a greater focus on the impact of menopause, which is associated with a number of negatively viewed appearance-related changes (McKinley \& Lyon, 2008). According to Slevec and Tiggemann (2011), women during menopause and perimenopause experience a change in hormone levels and a decreased metabolic rate, which are associated with weight gain, a redistribution of weight from the lower body, and a doubling of the percentage of body fat. These changes may amplify negative body experience and rates of disordered eating. In fact, a recent study reported that $43 \%$ of the sample of women with a median age of 51 were dissatisfied with their current bodies, and nearly $80 \%$ of the sample wanted to lose weight (Grippo \& Hill, 2008).

Although disordered eating and body dissatisfaction occur frequently in middle-aged women, little is known about the variables associated with these behaviors and attitudes in postmenopausal women. As with younger women, BMI seems to play an important role in the development of disordered eating and poor body image in middle-aged women (Algars et al., 2009; McLean et al., 2010). In fact, a number of studies support the association between high BMI and disordered eating in middle-aged women (Marcus et al., 2007; McLean et al., 2010). Thus, this study aimed to examine the impact of BMI (normal-weight postmenopausal women vs. overweight/obese postmenopausal women) on eating disturbances, body 
satisfaction, quality of life, and life satisfaction in a community sample of healthy postmenopausal women. This study also analyzed the predictors of disordered eating and life satisfaction in postmenopausal women. The predictors selected for this study included personal variables (e.g., age, BMI, ideal weight), sport variables (e.g., frequency of physical activity), and psychological variables (e.g., body satisfaction and quality of life). It is important to note that in this study life satisfaction was considered as an overall judgment made by the women about their life conditions (Diener, Emmons, Larsen, \& Griffin, 1985), whereas the term quality of life was related to the level of discomfort felt by women associated with symptoms of menopause (Hilditch et al., 1996).

Regarding the impact of BMI on eating disturbances and some psychological variables, there is evidence that BMI is an important risk factor impacting eating disturbance (Marcus et al., 2007; McLean et al., 2010), body dissatisfaction (Algars et al., 2009), and quality of life (Whiteman et al., 2003) during the postmenopausal period. Given the association between eating behavior and some health problems such as diabetes or hypertension that are associated with weight problems, the data regarding these variables in older women have implications for women's health care. Additionally, disordered eating and negative body image are also related to higher levels of depression and anxiety and lower self-esteem (Mortenson, Hoerr, \& Garner, 1993).

Regarding the predictors of disordered eating and life satisfaction, there is also evidence that menopausal transition may also lead to a decrease in psychological well-being and quality of life (QOL). For example, between $80 \%$ and $85 \%$ of American menopausal women complain of unpleasant symptoms that compromise women's QOL (North American Menopause Society [NAMS], 2000); however, very little is known about the relationship among weight, body satisfaction, and quality of life in healthy postmenopausal women. Some studies have reported a greater incidence of menopausal symptoms among women with a higher BMI (Gold et al., 2000; Whiteman et al., 2003), while others (e.g., Guthrie, Dennerstein, Taffe, Lehert, \& Burger, 2005) did not find that BMI or change in BMI was related to a higher incidence of menopausal symptoms. There is consensus in the literature that supports the beneficial effects of physical activity on both physical and psychological well-being during the postmenopausal period (Elavsky \& McAuley, 2005). In these studies, more physically active women reported less nervousness and fewer menopausal symptoms (Wilbur, Dan, Hedricks, \& Holm, 1990), as well as reductions in depressive states and reported symptoms of menopause (Schneider, 2002). The mechanisms underlying such effects, however, remain unclear. In fact, studies about the relationship among weight, physical activity, and quality of life are scarce. The body of research examining the role of age-related factors in middle-aged women, particularly menopause, is quite small, and thus, further studies are needed 
(Slevec \& Tiggemann, 2011). The biologically related weight gain and the increase in body fat that occurs at menopause may potentially affect eating behavior, body satisfaction, and life satisfaction during this stage.

Thus, the aims of this study were (a) to investigate the prevalence of disordered eating in postmenopausal women; (b) to evaluate differences between normal-weight postmenopausal women and overweight postmenopausal women in terms of eating patterns, physical activity, body satisfaction, quality of life, and life satisfaction; and (c) to evaluate which variables predict the development of disordered eating and life satisfaction in postmenopausal women.

\section{METHOD}

\section{Procedure}

This study was conducted in Portugal after being reviewed and approved by the internal review board of the Research Center of Psychology (University of Minho). The research conformed to both National and European regulations on conducting research with human participants and on the management of personal data. An initial request explaining the research goals and data collection procedures was sent to the public health service. After approval from the health service director was received, participants were invited to take part in the study and were assured that their information would remain anonymous and confidential. Only participants who agreed to these conditions were included in the study, and all participants were provided written informed consent before participating. This research was presented as a study of postmenopausal women's eating behaviors and quality of life.

\section{Participants}

In this study, 294 postmenopausal women between 44 and 85 years of age ( $M=58.83 ; S D=6.56)$ were recruited in the public health service. Women who had undergone a hysterectomy and/or bilateral oophorectomy were excluded from the study. The mean age of the onset of menopause was $49.32(S D=4.41)$. Four women $(1.4 \%)$ were from low social class, 224 (76.2\%) were from medium-low social class, 47 (16\%) were from medium social class, six (2\%) were from high-medium social class, and 13 (4.4\%) were from high social class. Regarding marital status, 14 (4.8\%) were single, 233 (79.3\%) were married/living together, 39 (13.3\%) were widows, and 8 (2.7\%) were divorced. Sixty-eight (23.1\%) women were normal weight, one (0.3\%) was underweight, 129 (43.9\%) were overweight, and 96 (32.6\%) were obese. Most of the women in the normal-weight group reported no weight (64.7\%) or eating habit changes (7.5\%) with menopause. In the overweight/obese group, $141(62.7 \%)$ of the women reported weight gain with menopause, 
and 146 (64.9\%) reported no changes in eating habits. Notably, groups did not differ in terms of age, $t(291)=-.18, p=.86$, and menopause onset age, $t(291)=-.55, p=.58$.

\section{Measures}

DEMOGRAPHIC AND CLINICAL INFORMATION

This measure assesses personal (e.g., gender, age, weight, height) and clinical information (e.g., age of onset of menopause, medical problems).

The Eating Disorder Examination Questionnaire (EDE-Q; Fairburn \& Beglin, 1994; Portuguese adaptation by Machado, 2007)

The EDE-Q assesses four subscales reflecting the severity of eating disorder symptoms over the past 28 days: (a) restraint $(\alpha=.62)$, (b) eating concern ( $\alpha=.48)$, (c) shape concern $(\alpha=.80)$, and (d) weight concern $(\alpha=.70)$. The instrument also includes a global score, which results from the average of the four subscale scores $(\alpha=.87)$. The EDE-Q also includes six items assessing specific behaviors related to eating disorders, with four of these items evaluating binge eating and compensatory behaviors over the past 28 days.

The Menopause-Specific Quality of Life Questionnaire (MENQOL; HiLDITCH ET AL., 1996)

The Menopause-Specific Quality of Life Questionnaire is a self-administered instrument that assesses the level of discomfort associated with symptoms of menopause. The MENQOL asks patients to indicate if they have a particular symptom (yes or no) and to evaluate the level of discomfort regarding a given symptom on a scale from 0 to 6. Symptoms include hot flashes, night sweats, feeling depressed, aching muscles or joints, difficulty sleeping, weight gain, dry skin, vaginal dryness, and sexual dysfunction. The 29 items yield four specific domains: (a) vasomotor (three items, $\alpha=.64$ ), (b) physical (seven items, $\alpha=.83$ ), (c) psychosocial (16 items, $\alpha=.70$ ), and (d) sexual (three items, $\alpha=.87$ ). Each item is scored from 1 to 8 , with the final score for each domain representing a mean of the items in that domain. Higher scores on this scale indicate greater degree of symptom discomfort or less favorable quality of life. The questionnaire was translated into Portuguese. To ensure an adequate translation, it was translated back into English, and this new version was again translated into Portuguese (backward-translate technique). 


\section{Exercise Behavior Evaluation (EBE; Cruz \& Gomes, 2006)}

This instrument establishes the participants' current level of regular exercise. EBE starts by defining regularpractice of exercise as engaging in the behavior for at least 30 minutes at least three times per week. It also describes what doing exercise means (e.g., assuming the practice of an intensive and specific exercise activity, for example, swimming, running, etc.). It also indicated that this activity was different than the usual routines of physical activity (for example, walking or running to take a bus). Participants had to choose one of the following options: (a) don't do exercise and don't intend to do it, (b) don't do exercise but have already assumed the intention to do it in the next four weeks, (c) do exercise occasionally (e.g., less than three times per week), (d) had already done exercise in the last six months but don't do it at the present time, and (e) do exercise at least three times per week for at least 30 minutes (Lippke, Ziegelmann, \& Schwarzer, 2005; Schwarzer, 1992).

AThletic Condition Questionnaire (ACQ; Gomes, Martins, \& Silva, 2011)

For the purpose of this study, participants responded to three items from one subscale of this questionnaire that evaluates satisfaction with body shape and physical appearance. Responses were scored on a Likert-scale ranging from 1 (extremely dissatisfied) to 5 (extremely satisfied) (e.g., "I am satisfied with my weight"). The score was obtained by adding item values and dividing the sum by the total number of items forming the subscale $(\alpha=.80)$.

The Satisfaction With Life Scale (SWLS; Diener et Al., 1985; Portuguese adaptation By Neto, 1993)

This instrument includes five items and evaluates respondents' subjective judgments about their quality of life. Responses were scored on a Likertscale ranging from 1 (totally disagree) to 7 (totally agree). The scores were obtained by adding item values, and the sum was then divided by the total number of items forming the subscale. Higher values indicate greater satisfaction with life $(\alpha=.80)$.

The internal consistency was acceptable for most of the scales $(\alpha>.70)$; however, the values on the eating concern scale of the EDE-Q instrument were below the acceptable level, and for that reason, this dimension was removed from the final analysis. In addition, for this instrument, the alpha value of the restraint scale was achieved by removing item 2 from the analysis, which increased the value from .59 to .62 (reducing the number of items in the scale to four). The four-item restraint scale and the vasomotor dimension of the MENQOL instrument (with three items) were maintained on the 
analysis (both with alpha values above .60) due to the existence of four or fewer items per scale (Cortina, 1993).

\section{DATA ANALYSIS}

First, an exploratory data analysis examined parametric test assumptions. We did not find assumption violations in most cases. In cases where normality was not assumed, we computed parametric test statistics and their nonparametric equivalents. The results from both tests allowed us to make the same general conclusions. As such, we present only the parametric test results because they are more robust and allow us to use multivariate analyses, thereby reducing the number of tests conducted and the probability of establishing a Type I error.

To evaluate the associations between nominal variables, chi-squared tests were conducted. To evaluate between-group differences with regard to BMI, independent-samples $t$-tests were conducted. To evaluate betweengroup differences with regard to EDE-Q and MENQOL scores, we applied multivariate analyses of variance. To predict disordered eating behavior and life satisfaction, we used a regression analysis with a blocked entry procedure.

\section{RESULTS}

Disordered Eating and Body Satisfaction Among Normal-Weight and Overweight Menopausal Women

With eating disorder behaviors coded as either present or absent over the previous four weeks, a chi-squared analysis revealed no significant differences between groups in binge-eating episodes (28\% vs. 32.4\%, for normal-weight vs. overweight women respectively, $p=.69$ ), self-induced vomiting $(0.4 \%$ vs. $0 \%$, for normal-weight vs. overweight women respectively, $p=.16$ ), laxative use ( $0 \%$ for both groups), and excessive exercise $(2.2 \%$ vs. $1.5 \%$, for normal-weight vs. overweight women respectively, $p=1.0$ ). Significant differences in the three dimensions of the Eating Disorder Examination Questionnaire (EDE-Q) were found, Wilks' $\lambda=.81$, $F(3,289)=22.31, p<.001, \eta^{2}=.18$. Univariate tests showed that the overweight group had higher scores on all the dimensions of EDE-Q. Likewise, this group scored higher on the EDE-Q global score, $t(291)=8.16, p<.001$. All significant results from these analyses can be found in Table 1.

Regarding body satisfaction, 5.7\% of the normal-weight group and 94.3\% of the overweight group reported a desire for a lower weight, $\chi^{2}(1)=74.62$, $p<.001$. As expected, normal-weight postmenopausal women reported 
TABLE 1 Differences Between the Groups in Eating Disorder Behaviors

\begin{tabular}{|c|c|c|c|}
\hline & Normal-Weight Group & Overweight Group & \\
\hline & $\begin{array}{c}(n=68) \\
M(S D)\end{array}$ & $\begin{array}{c}(n=225) \\
M(S D)\end{array}$ & $\begin{array}{c}F \\
(1,288)\end{array}$ \\
\hline EDE-Q: Restraint & $1.15(1.46)$ & $2.15(1.52)$ & $23.14^{* * *}$ \\
\hline EDE-Q: Shape concern & $.68(.63)$ & $2.08(1.42)$ & $62.07^{* * *}$ \\
\hline \multirow[t]{2}{*}{ EDE-Q: Weight concern } & $.48(.51)$ & 1.57 (1.19) & $53.39^{* * *}$ \\
\hline & $M(S D)$ & $M(S D)$ & $t(291)$ \\
\hline EDE-Q: Global score & $.74(.60)$ & $1.94(1.17)$ & $8.16^{* * *}$ \\
\hline Body satisfaction & $4.00(.83)$ & $3.07(.94)$ & $-7.34^{* * *}$ \\
\hline
\end{tabular}

${ }^{*} p<.05 ;{ }^{* *} p<.01 ;{ }^{* * *} p<.001$.

higher scores on the body satisfaction questionnaire compared to overweight postmenopausal women, $t(291)=-7.34, p<.001$.

Physical Activity Among Normal-Weight and Overweight Menopausal Women

Almost $42 \%$ ( $n=94)$ of the overweight menopausal women exercised regularly. In the group of normal-weight postmenopausal women, 39.7\% $(n=27)$ exercised regularly. No association was found between weight and exercise, $\chi^{2}(1)=.09, p=.78$.

\section{Quality of Life and Life Satisfaction Among Normal-Weight and} Overweight Menopausal Women

Significant differences in the four dimensions of the Menopause-Specific Quality of Life questionnaire were found, Wilks' $\lambda=.95, F(4,288)=3.79$, $p=.005, \eta^{2}=05$. Univariate tests showed that the normal-weight group had higher scores on the physical domain, $F(1,291)=13.59 ; p<.001, \eta^{2}=.05$. No significant differences between groups were found on the life satisfaction questionnaire $(p=.56)$. These results can be found in Table 2 .

To test if quality of life was related to exercise practice in postmenopausal women, four groups were created: (a) normal weight with regular exercising, (b) normal weight without regular exercising, (c) overweight with regular exercising, and (d) overweight without regular exercising. ANOVA results showed significant differences between groups only on the physical domain of the quality of life questionnaire, $F(3,285)=5.08$, $p=.002$. Scheffé post hoc results showed that normal-weight women who exercised regularly reported higher physical quality of life compared to normal-weight women who did not exercise regularly $(p=.01)$ and to overweight women who did not exercise regularly $(p=.04)$. 
TABLE 2 Differences Between the Groups in Quality of Life and Life Satisfaction

\begin{tabular}{|c|c|c|c|}
\hline & Normal-Weight Group & Overweight Group & \\
\hline & $\begin{array}{c}(n=68) \\
M(S D)\end{array}$ & $\begin{array}{c}(n=225) \\
M(S D)\end{array}$ & $F$ \\
\hline \multicolumn{4}{|l|}{ Quality of life } \\
\hline Physical domain & $3.87(1.49)$ & $4.62(1.48)$ & $13.59^{* * *}$ \\
\hline Vasomotor domain & $3.60(2.27)$ & $3.92(2.35)$ & .98 \\
\hline Psychosocial domain & $3.69(1.56)$ & $4.06(1.57)$ & $2.91+$ \\
\hline \multirow[t]{2}{*}{ Sexual domain } & $3.35(2.46)$ & $3.55(2.56)$ & .30 \\
\hline & $\begin{array}{c}(n=223) \\
M(S D)\end{array}$ & $\begin{array}{c}(n=68) \\
M(S D)\end{array}$ & $t(291)$ \\
\hline Life satisfaction & $5.30(1.32)$ & $5.42(1.42)$ & .61 \\
\hline
\end{tabular}

\section{Predictors of Disordered Eating and Life Satisfaction in} Postmenopausal Women

Two regression analyses were conducted to predict disordered eating and life satisfaction using the global scores of the EDE-Q and SWLS. Variables were entered in the following order: (a) age, (b) BMI (setting two groups: the participants who were overweight and the participants who were of normal weight), (c) ideal weight (setting two groups: the participants with a perception of ideal weight lower than their current weight and the participants that desired to maintain or even increase their current weight), (d) physical activity (setting two groups: the participants who did not exercise regularly and the participants who exercised regularly), (e) body satisfaction (considering the participants' scores in the scale of Satisfaction with Body Shape and Physical Appearance), and (f) quality of life dimensions (considering the participants' scores in the scale of Menopause-Specific Quality of Life). These models did not reveal multicollinearity problems, and the data were normally distributed (Tabachnick \& Fidell, 2001).

Starting with the prediction of disordered eating, the first block was significant, showing that the increase of age predicted a lower tendency toward disordered eating. BMI in the second block was also significant; being overweight predicted disordered eating. In the third block, the perception of ideal weight was significant because the perception of an ideal weight lower than one's current weight predicted disordered eating. Block four regarding physical activity was not significant. Block five showed that less satisfaction with body shape and physical appearance predicted disordered eating. In the final block, disordered eating was predicted by more physical discomfort associated with symptoms of menopause as well as marginally significant results for the psychosocial dimension of the MENQOL. These results can be found in Table 3. 
TABLE 3 Regression Model for the Prediction of Disordered Eating and Life Satisfaction

\begin{tabular}{|c|c|c|c|c|}
\hline & \multicolumn{4}{|c|}{ Disordered Eating } \\
\hline & $R^{2}\left(\operatorname{Adj} . R^{2}\right)$ & $F$ & $\beta$ & $T$ \\
\hline Block 1 & $.02(.01)$ & $(1,291)$ & & \\
\hline Age & & 6.12 & -.14 & $-.2 .47^{*}$ \\
\hline Block 2 & $.21(.19)$ & $(2,290)$ & & \\
\hline $\mathrm{BMI}^{\mathrm{a}}$ & & 37.36 & -.43 & $-.8 .19^{*}$ \\
\hline Block 3 & & $(3,289)$ & & \\
\hline Ideal weight ${ }^{\mathrm{b}}$ & $.41(.41)$ & 67.88 & -.53 & $-10.13^{* * *}$ \\
\hline Block 4 & & $(4,288)$ & & \\
\hline Physical activity ${ }^{\mathrm{c}}$ & $.42(.41)$ & 51.38 & .06 & $1.24^{+}$ \\
\hline Block 5 & & $(5,287)$ & & \\
\hline Body satisfaction & $.52(.51)$ & 62.51 & -.40 & $-7.93^{* * *}$ \\
\hline Block 6 & & $(9,283)$ & & \\
\hline Quality of life dimensions & $.55(.54)$ & 38.90 & & \\
\hline Vasomotor & & & -.05 & $-.95 \mathrm{~ns}$ \\
\hline Psychosocial & & & .11 & $1.85^{+}$ \\
\hline Physique & & & .13 & $2.12^{*}$ \\
\hline \multirow[t]{2}{*}{ Sexual } & & & -.00 & $-.06 \mathrm{~ns}$ \\
\hline & \multicolumn{4}{|c|}{ Life Satisfaction } \\
\hline Block 1 & $.01(.00)$ & $(1,291)$ & .76 & $1.33 \mathrm{~ns}$ \\
\hline Age & & 1.77 & & \\
\hline Block 2 & $.01(.00)$ & $(2,290)$ & -.03 & $-.63 \mathrm{~ns}$ \\
\hline $\mathrm{BMI}^{\mathrm{a}}$ & & 1.08 & & \\
\hline Block 3 & $0.1(.00)$ & $(3,289)$ & .08 & $1.21 \mathrm{~ns}$ \\
\hline Ideal weight $^{\mathrm{b}}$ & & 1.21 & & \\
\hline Block 4 & $0.1(.00)$ & $(4,288)$ & .06 & $.76 \mathrm{~ns}$ \\
\hline Physical activity $^{c}$ & & 1.05 & & \\
\hline Block 5 & $.11(.09)$ & $(5,287)$ & .39 & $5.65^{* * *}$ \\
\hline Body satisfaction & & 7.32 & & \\
\hline Block 6 & $.19(.16)$ & $(9,283)$ & & \\
\hline Quality of life dimensions & & $7.59^{*}$ & & \\
\hline Vasomotor & & & .07 & $1.03 \mathrm{~ns}$ \\
\hline Psychosocial & & & .36 & $-4.61^{* * *}$ \\
\hline Physique & & & .09 & $1.01 \mathrm{~ns}$ \\
\hline Sexual & & & .13 & $2.28^{*}$ \\
\hline
\end{tabular}

Note. ${ }^{\mathrm{a}} \mathrm{BMI}$ : $0=$ overweight; $1=$ normal weight; ${ }^{\mathrm{b}}$ Perception of Ideal Weight: $0=$ lower than the current weight; $=$ same or higher than current weight; ${ }^{c}$ Physical activity: $0=$ no regular practice; $1=$ regular practice.

${ }^{+} p<.10 ;{ }^{*} p<.05 ;{ }^{* *} p<.01 ;{ }^{* * *} p<.001 ;$ n.s. $=$ not significant.

For life satisfaction, the first four blocks including age, BMI, perception of ideal weight, and engaging in physical activity were not significant. The fifth block was significant as greater satisfaction with body shape and physical appearance predicted greater life satisfaction. In the final block, life satisfaction was predicted by less psychosocial discomfort associated with the symptoms of menopause and, unexpectedly, by a greater degree of sexual symptom discomfort. 


\section{DISCUSSION}

This study aimed to evaluate differences between normal-weight and overweight postmenopausal women in terms of eating patterns, body satisfaction, physical activity, quality of life, and life satisfaction. It also aimed to evaluate the predictors of disordered eating and life satisfaction in postmenopausal women.

Compared to the normal-weight group, overweight postmenopausal women in our study reported higher scores on EDE-Q subscales. The overweight group reported high restraint, eating concern, and shape and weight concern. Although previous studies support the fact that disordered eating occurs frequently in older women, our study highlights that these disordered eating behaviors occur more frequently in overweight/obese postmenopausal women. However, few women in both groups reported extreme compensatory behaviors. This may mean that older women use less extreme compensatory behaviors than younger women and prefer the eating restraint to weight control. Previous studies (e.g., Lawson et al., 1995; Williamson et al., 1995) also found a significant positive association between restraint scores with BMI.

According to our results, $5.7 \%$ of the normal-weight group and $94.3 \%$ of the overweight group reported a desire for a lower weight, and normalweight postmenopausal women reported higher scores on the body satisfaction questionnaire compared to overweight postmenopausal women. The literature consistently documents that overweight/obese postmenopausal women report higher body dissatisfaction than normal-weight women (Algars et al., 2009; Dunkel, Davidson, \& Qurashi, 2010; McLean et al., 2010). For example, McLaren and Kuh (2004) found that only a few obese women were "happy" with their weight, thus supporting this relationship between BMI and body satisfaction among middle-aged women. Our results also showed that levels of disordered eating and body dissatisfaction in overweight Portuguese postmenopausal women are quite similar to those found in other countries (Peat, Peyerl, \& Muehlenkamp, 2008) and provide additional support for previous studies that showed that body dissatisfaction and disordered eating are common in postmenopausal women in different cultures (Hrabosky \& Grilo, 2007; Owens, Hughes, \& Owens-Nicholson, 2002).

Regarding physical activity and the postmenopausal period, a large body of research has established that regular physical activity reduces the risk of premature death and disability from a variety of health conditions for postmenopausal women (U.S. Department of Health and Human Services, 1996) and that more physically active women reported fewer menopausal symptoms than did women with a sedentary lifestyle (Moilanen et al., 2010). According to our study, almost $40 \%$ of the normal-weight women and $42 \%$ of the overweight women reported being physically active. These results are 
lower than the patterns of physical activity reported, for example, by U.S. women 40 years and older, and they emphasize the need for educational programs and public health recommendations for this age population to include a "lifestyle" approach of increasing activity. As expected, normalweight women who exercised regularly reported higher physical quality of life compared to normal-weight women who did not and to overweight women who did not exercise regularly. Our results are in line with previous studies that show the effects of exercise on muscle strength, bone density, and on the postmenopausal symptoms (Agre, Pierce, Raab, McAdams, \& Smith, 1988; Sharkey, Williams, \& Guerin, 2000).

According to our results, overweight postmenopausal women present lower quality of life only in the physical domain. This was an unexpected result, considering that previous research shows a higher BMI was significantly associated with a higher number of psychological and vasomotor symptoms among middle-aged women (Moilanen et al., 2010; Thurston et al., 2008; Whiteman et al., 2003). Additionally, no significant differences were found when comparing normal-weight women to overweight women on measures of life satisfaction. One possibility may account for this. The importance placed on weight in postmenopausal women for the evaluation of life satisfaction and quality of life is not as essential as for younger women. The literature appears to indicate that women experience body dissatisfaction throughout their lives, but the extent of the negative impact that body dissatisfaction has on self-concept may lessen with age (Peat et al., 2008; Tiggemann, 2004).

Our results suggest that disordered eating in postmenopausal women was predicted by age, BMI, ideal weight, body satisfaction, and physical quality of life. Younger women seem to be at a higher risk than older women for presenting disordered eating. These results seem to be congruent with other studies that show younger women as having more drive for thinness and disinhibited eating than older women. For example, Lewis and Cachelin (2001) compared middle-aged women with an elderly group of women and found that the middle-aged group reported higher levels of disordered eating. Not surprisingly, higher BMI emerged as a predictor of disordered eating in this stage of life. According to Slevec and Tiggemann (2011), BMI is considered to play an important role in promoting eating disturbances. A number of cross-sectional studies (Hrabosky \& Grilo, 2007) and one longitudinal study (McCabe, Ricciardelli, \& James, 2007) support the association between BMI and disordered eating in middle-aged women. For example, in the study of McLean et al. (2010), participants identified as probable eating disorder cases had significantly higher BMIs. Marcus et al. (2007) found that a BMI of 30 or higher was a unique predictor of eating disorder symptoms in middle-aged women. However, to the best of our knowledge, this is the first study that evaluates the role of weight in the presence of eating disordered behavior in the postmenopausal period. Body 
dissatisfaction also emerged as a significant predictor of disordered eating. Among middle-aged women, body dissatisfaction was consistently associated with dieting (Bennett \& Stevens, 1996) and disordered eating and behaviors (Hrabosky \& Grilo, 2007; Marcus et al., 2007; McLean et al., 2010). Slevec and Tiggemann (2011) suggest that future studies should test whether body dissatisfaction mediates the relationship between BMI and disordered eating in women of this age group. Our results suggest that body satisfaction predicts life satisfaction in postmenopausal women. This result was surprising. In fact, the literature appears to indicate that women experience body satisfaction throughout their lives, but the extent of the negative impact that body satisfaction has on self-concept and life in general may lessen with age (Peat et al., 2008). Our results did not confirm this assumption but highlight the fact that body satisfaction seems to be related to life satisfaction at this life stage. As expected, psychosocial quality of life also emerged as a predictor of life satisfaction.

The limitations of this study include the retrospective, cross-sectional nature of our adopted design and its reliance on self-report questionnaires. Replication using larger samples and longitudinal designs are required to determine the predictors and correlations of eating disturbances and life satisfaction with postmenopausal women. Another limitation was the use of BMI for the determination of normal versus overweight women. Although, BMI is widely accepted within professionals groups as the "gold standard" to classify overweight and obesity in adults, there are many variables that question this objectivity, especially in older individuals. According to Cook, Kirk, Lawrenson, and Sandford (2005), BMI is not an appropriate tool for use with individuals or in populations for whom body composition may be different from that of healthy younger adults.

In summary, our results point to a high prevalence of eating disturbance and body dissatisfaction among overweight/obese postmenopausal women compared to normal-weight postmenopausal women. The overweight group also reported lower quality of life on the physical domain. Results also showed that the increase of age predicted a lower tendency to developing disordered eating, but higher BMI, the perception of an ideal weight lower than the current one, less satisfaction with body shape and physical appearance, and lower physical quality of life predicted disordered eating in postmenopausal women. The results also showed that more satisfaction with body shape and physical appearance, less psychosocial discomfort associated with symptoms of menopause, and unexpectedly, a greater degree of sexual symptom discomfort predicted life satisfaction. It is noteworthy that in our study overweight and body dissatisfaction are related to negative consequences in postmenopausal women. Public health interventions will need to consider strategies to promote both appropriate weight-control efforts and positive body image in postmenopausal women. 


\section{REFERENCES}

Agre, C. J., Pierce, E. L., Raab, M. D., McAdams, M., \& Smith, L. E. (1988). Light resistance and stretching exercise in elderly women: Effect upon strength. Archives of Physical Medicine and Rehabilitation, 69, 273-276.

Algars, M., Santtila, P., Varjonen, M., Witting, K., Johansson, A., Jern, P., \& Sandnabba, N. K. (2009). The adult body: How age, gender, and body mass index are related to body image. Journal of Aging and Health, 21, 1112-1132. doi: $10.1177 / 0898264309348023$

Bennett, K., \& Stevens, R. (1996). Weight anxiety in older women. European Eating Disorders Review, 4, 32-39. doi:10.1002/(SICI)1099-0968(199603) 4:1<32::AID-ERV113>3.0.CO;2-S

Cook, Z., Kirk, S., Lawrenson, S., \& Sandford, S. (2005). Use of BMI in the assessment of undernutrition in older subjects: Reflecting on practice. Proceedings of the Nutrition Society, 64, 313-317. doi:10.1079/PNS2005437

Cortina, J. M. (1993). What is coefficient alpha? An examination of theory and applications. Journal of Applied Psychology, 78, 98-104. doi:10.1037/ 0021-9010.78.1.98

Cruz, J. F., \& Gomes, A. R. (2006). Escala de comportamentos face ao exercicio físico [Exercise behavior evaluation]. Unpublished manuscript, Universidade do Minho, Braga, Portugal.

Diener, E., Emmons, R., Larsen, R., \& Griffin, S. (1985). The satisfaction with life scale. Journal of Personality Assessment, 49, 71-75. doi:10.1207/ s15327752jpa4901_13

Dunkel, T. M., Davidson, D., \& Qurashi, S. (2010). Body satisfaction and pressure to be thin in younger and older Muslim and non-Muslim women: The role of Western and non-Western dress preferences. Body Image, 7, 56-65. doi:10.1016/j.bodyim.2009.10.003

Elavsky, S., \& McAuley, E. (2005). Physical activity, symptoms, esteem, and life satisfaction during menopause. Maturitas, 52, 374-385. doi:10.1016/ j.maturitas.2004.07.014

Fairburn, C. G., \& Beglin, S. J. (1994). The assessment of eating disorders: Interview or self-report questionnaire?. International Journal of Eating Disorders, 16, 363-370.

Freitas, S. R., Appolinario, J. C., Souza, A. M., \& Sichieri, R. (2008). Prevalence of binge eating and associated factors in a Brazilian probability sample of midlife women. International Journal of Eating Disorders, 41, 471-478. doi:10.1002/eat.20530

Gold, E. B., Sternfeld, B., Kelsey, J. L., Brown, C., Mouton, C., Reame, N., ... Stellan, R. (2000). Relation of demographic and lifestyle factors to symptoms in a multiracial/ethnic population of women 40-55 years of age. American Journal of Epidemiology, 152, 463-473. doi:10.1093/aje/152.5.463

Gomes, A. R., Martins, C., \& Silva, L. (2011). Eating disordered behaviours in Portuguese athletes: The influence of personal, sport, and psychological variables. European Eating Disorders Review, 19(3), 190-200. doi:10.1002/erv.1113

Gravener, J. A., Haedt, A. A., Heatherton, T. F., \& Keel, P. K. (2008). Gender and age differences in associations between peer dieting and drive for thinness. International Journal of Eating Disorders, 41, 57-63. doi:10.1002/eat.20438 
Grippo, K. P., \& Hill, M. S. (2008). Self-objectification, habitual body monitoring, and body dissatisfaction in older European American women: Exploring age and feminism as moderators. Body Image, 5, 173-182. doi:10.1016/j.bodyim.2007.11.003

Guthrie, J. R., Dennerstein, L., Taffe, J. R., Lehert, P., \& Burger, H. G. (2005). Hot flushes during the menopause transition: A longitudinal study in Australian-born women. Menopause (New York, N.Y.), 12, 460-467. doi:10.1097/01.GME.0000155200.80687.BE

Hilditch, J. R., Lewis, J., Peter, A., Van Maris, B., Ross, A., Franssen, E., ... Dunn, E. (1996). A menopause-specific quality of life questionnaire: Development and psychometric properties. Maturitas, 24, 161-175. doi:10.1016/S0378-5122(96)82006-8

Hrabosky, J. I., \& Grilo, C. M. (2007). Body image and eating disordered behavior in a community sample of Black and Hispanic women. Eating Behaviors, 8, 106-114. doi:10.1016/j.eatbeh.2006.02.005

Johnson, J. G., Spitzer, R. L., \& Williams, J. B. W. (2001). Health problems, impairment and illnesses associated with bulimia nervosa and binge eating disorder among primary care and obstetric gynaecology patients. Psychological Medicine, 31, 1455-1466. doi:10.1017/S0033291701004640

Keel, P. K., Gravener, J. A., Joiner, T. E., Jr., \& Haedt, A. A. (2010). Twentyyear follow-up of bulimia nervosa and related eating disorders not otherwise specified. International Journal of Eating Disorders, 6, 492-497. doi:10.1002/eat.20743

Lawson, O. J., Williamson, D. A., Champagne, C. M., DeLany, J. P., Brooks, E. R., Howat, P. M., ... Ryan, D. H. (1995). The association of body weight, dietary intake, and energy expenditure with dietary restraint and disinhibition. Obesity Research, 3, 153-161. doi:10.1002/j.1550-8528.1995.tb00131.x

Lewis, D. M., \& Cachelin, F. M. (2001). Body image, body dissatisfaction, and eating attitudes in midlife and elderly women. Eating Disorders, 9, 29-39. doi:10.1080/106402601300187713

Lippke, S., Ziegelmann, J. P., \& Schwarzer, R. (2005). Stage-specific adoption and maintenance of physical activity: Testing a three-stage model. Psychology of Sport and Exercise, 6, 585-603. doi:10.1016/j.psychsport.2004.11.002

Lucas, A. R., Beard, C. M., O'Fallon, W., \& Kurland, L. T. (1991). 50 year trends in the incidence of anorexia nervosa in Rochester Minnesota: A population based study. The American Journal of Psychiatry, 7, 917-922.

Lucas, A. R., Crowson, C. S., O'Fallon, W. M., \& Melton, L. J. (1999). The ups and downs of anorexia nervosa. International Journal of Eating Disorders, 26, 397-405. doi:10.1002/(SICI)1098-108X(199912)26:4<397::AID-EAT5>3.0.CO;2-0

Machado, P. P. P. (2007). Questionário de alimentação: EDE-Q5.2 [Eating Questionnaire: EDE-Q5.2]. Centro de Investigação em Psicologia. Braga, Portugal: Universidade do Minho.

Marcus, M. D., Bromberger, J. T., Wei, H.-L., Brown, C., \& Kravitz, H. M. (2007). Prevalence and selected correlates of eating disorder symptoms among a multiethnic community sample of midlife women. Annals of Behavioral Medicine, 33, 269-277. doi:10.1007/BF02879909 
McCabe, M. P., Ricciardelli, L. A., \& James, T. (2007). A longitudinal study of body change strategies of fitness center attendees. Eating Behaviors, 8, 492-496. doi:10.1016/j.eatbeh.2007.01.004

McKinley, N. M., \& Lyon, L. A. (2008). Menopausal attitudes, objectified body consciousness, aging anxiety, and body esteem: European American women's body experiences in midlife. Body Image, 5, 375-380. doi:10.1016/ j.bodyim.2008.07.001

McLaren, L., \& Kuh, D. (2004). Body dissatisfaction in midlife women. Journal of Women and Aging, 16, 35-54. doi:10.1300/J074v16n01_04

McLean, S. A., Paxton, S. J., \& Wertheim, E. H. (2010). Factors associated with body dissatisfaction and disordered eating in women in midlife. International Journal of Eating Disorders, 43, 527-536. doi:10.1002/eat.20737

Moilanen, J., Aalto, A.-M., Hemminki, E., Aro, A. R., Raitanen, J., \& Luoto, R. (2010). Prevalence of menopause symptoms and their association with lifestyle among Finnish middle-aged women. Maturitas, 67, 368-374. doi:10.1016/j.maturitas.2010.08.007

Mortenson, G. M., Hoerr, S. L., \& Garner, D. M. (1993). Predictors of body satisfaction in college women. Journal of the American Dietetic Association, 93, 1037-1039. doi:10.1016/0002-8223(93)92044-X

North American Menopause Society (NAMS). (2000). Menopause core curriculum study guide. Cleveland, $\mathrm{OH}$ : Author.

Neto, F. (1993). The satisfaction with life scale: Psychometrics properties in an adolescent sample. Journal of Youth and Adolescence, 22, 125-134. doi:10.1007/BF01536648

Owens, L. K., Hughes, T. L., \& Owens-Nicholson, D. (2002). The effects of sexual orientation on body image and attitudes about eating and weight. Journal of Lesbian Studies, 7, 15-33. doi:10.1300/J155v07n01_02

Peat, C. M., Peyerl, N. L., \& Muehlenkamp, J. J. (2008). Body image and eating disorders in older adults: A review. The Journal of General Psychology, 135, 343-358. doi:10.3200/GENP.135.4.343-358

Pérez, M., Hernández, A., Clarke, A., \& Joiner, T. E., Jr. (2007). Analysis of bulimic symptomatology across age and geographic locations. Eating Behaviors, 1, 136-142. doi:10.1016/j.eatbeh.2006.02.001

Pike, K. M., Hilbert, A., Wilfley, D. E., Fairburn, C. G., Dohm, F.-A., Walsh, B. T., \& Striegel-Moore, R. (2008). Toward an understanding of risk factors for anorexia nervosa: A case-control study. Psychological Medicine, 38, 1443-1453. doi:10.1017/S0033291707002310

Schneider, H. P. G. (2002). The quality of life in the post-menopausal woman. Best Practice \& Research Clinical Obstetrics \& Gynaecology, 3, 305-409.

Schwarzer, R. (1992). Self-efficacy in the adoption and maintenance of bealth behaviors: Theoretical approaches and a new model. In R. Schwarzer (Ed.), Selfefficacy: Thought control of action (pp. 217-243). Washington, DC: Hemisphere.

Sharkey, A. N., Williams, I. N., \& Guerin, B. J. (2000). The role of exercise in the prevention and treatment of osteoporosis and osteoarthritis. Nurse Clinical Northern America, 35, 209-221.

Slevec, J. H., \& Tiggemann, M. (2011). Predictors of body dissatisfaction and disordered eating in middle-aged women. Clinical Psychology Review, 31, 515-524. doi:10.1016/j.cpr.2010.12.002 
Tabachnick, B. G., \& Fidell, L. S. (2001). Using multivariate statistics (4th ed.). New York, NY: HarperCollins,

Thurston, R. C., Sowers, M. R., Chang, Y., Sternfeld, B., Gold, E. B., Johnston, J. M., \& Matthews, K. A. (2008). Adiposity and reporting of vasomotor symptoms among midlife women: The study of women's health across the nation. American Journal of Epidemiology, 167, 78-85. doi:10.1093/aje/kwm244

Tiggemann, M. (2004). Body image across the adult life span: Stability and change. Body Image, 1, 29-41. doi:10.1016/S1740-1445(03)00002-0

U.S. Department of Health and Human Services. (1996). Physical activity and health: A report of the surgeon general. Atlanta, GA: Centers for Disease Control and Prevention.

Whiteman, M. K., Staropoli, C. A., Langenberg, P. W., McCarter, R. J., Kjerusff, K. A., \& Flaws, J. A. (2003). Smoking, body mass, and hot flashes in midlife women. Obstetrics and Gynecology, 101, 264-273. doi:10.1016/S0029-7844(02)02593-0

Wilbur, J. E., Dan, A., Hedricks, C., \& Holm, K. (1990). The relationship among menopausal status, menopausal symptoms, and physical activity in midlife women. Family \& Community Health, 13, 67-78. doi:10.1097/ 00003727-199011000-00009

Williamson, D. A., Lawson, O. J., Brooks, E. R., Wozniak, P. J., Ryan, D. H., Bray, G. A., \& Duchmann, E. G. (1995). Association of body mass with dietary restraint and disinhibition. Appetite, 25, 31-41. doi:10.1006/appe.1995.0039 